\title{
PEMANFAATAN MEDIA PROMOSI KESEHATAN DALAM PEMBERDAYAAN PROGRAM DIET GADGET BAGI SISWA SEKOLAH DASAR
}

\author{
UTILIZATION OF HEALTH PROMOTION MEDIA IN EMPOWERING \\ THE GADGET DIET PROGRAM FOR PRIMARY SCHOOL STUDENTS
}

\author{
Heldie Bramantha \\ Universitas Abdurachman Saleh Situbondo \\ Email: heldiebramantha86@gmail.com
}

\begin{abstract}
Abstrak: Penggunaan gadget dikalangan anak-anak semakin memprihatinkan dan tentu memiliki dampak negatif terhadap tumbuh kembang. Terlihat jelas anak-anak lebih cepat beradaptasi dengan teknologi yang ada. Sehingga anak-anak sering terlena dengan kecanggihan gadget dengan fitur-fitur yang tersedia di dalamnya. Tujuan dari pengabdian masyarakat ini adalah sebagai salah satu upaya untuk menurunkan dampak negatif gadget pada siswa sekolah dasar. Sasaran dari pengabdian masyarakat ini adalah siswa sekolah dasar di Kecamatan Mangaran Kota Situbondo. Kegiatan dilaksanakan di SDN 1 Tanjung Glugur Kota Situbondo. Target Luaran yang dicapai dalam kegiatan pengabdian ini adalah siswa memperoleh informasi tentang cara menggunakan gadget dengan bijak. Kegiatan pengabdian ini menggunakan alat bantu berupa media promosi kesehatan yaitu media permainan ular tangga untuk mempermudah dalam menyampaikan informasi kepada peserta serta media ini juga bisa digunakan untuk belajar sekaligus bermain sehingga para siswa sangat antusias dalam mengikuti kegiatan ini. Evaluasi dari kegiatan ini yaitu tim melakukan pendampingan kepada siswa SDN 1 Tanjung Glugur. Pendampingan ini di lakukan selama 3 minggu. Setelah dilakukan pendampingan, terlihat siswa yang awalnya ketika jam istirahat selalu bermain gadget, sudah mulai meninggalkan gadget ketika di sekolah
\end{abstract}

Kata Kunci: Diet Gadget, Media Promosi Kesehatan, Siswa Sekolah Dasar

\begin{abstract}
The use of gadgets among children is increasingly alarming and certainly has a negative impact on growth and development. It is clear that children adapt faster to existing technology. So that children often fall asleep with the sophistication of the gadget with the features available in it. The purpose of community service is as an effort to reduce the negative impact of gadgets on elementary school students. The target of this community service is elementary school students in Mangaran City, Situbondo District. The activity was held at SDN 1 Tanjung Glugur City of Situbondo. The target output achieved in this service activity is students get information about how to use gadgets wisely. This service activity uses a tool in the form of health promotion media, which is a snake ladder playing media to make it easier to convey information to participants and this media can also be used for learning and playing so students are very enthusiastic in participating in this activity. The evaluation of this activity was that the team provided assistance to students at SDN 1 Tanjung Glugur. This assistance is done for 3 weeks. After the mentoring was done, it was seen that students who initially played at rest always played gadgets, had started leaving their gadgets when they were at school

Keywords: Diet Gadget, Health Promotion Media, Elementary School Students
\end{abstract}




\section{INTEGRITAS : Jurnal Pengabdian}

Vol 4, No 2, Desember 2020

ISSN 2580 - 7978 (cetak) ISSN 2615 - 0794 (online)

\section{PENDAHULUAN}

Gawai atau dalam istilah bahasa asing biasa dikenal dengan sebutan gadget merupakan suatu piranti atau instrumen yang memiliki tujuan dan fungsi praktis yang secara spesifik dirancang lebih canggih dibandingkan dengan teknologi yang diciptakan sebelumnya. Keberadaan gadget memberikan banyak manfaat bagi kehidupan manusia. Kecanggihan teknologi mempermudah pekerjaan manusia dan memungkinkan akses informasi tanpa harus terhalang ruang dan waktu. Akan tetapi kecanggihan teknologi ini juga dapat menjadi bumerang bagi kita jika tidak bijak dalam menggunakannya.

Pada zaman sekarang bukan menjadi suatu hal yang asing saat kita menemui anak-anak. Penggunaan gadget dikalangan anak-anak semakin memprihatinkan dan tentu memiliki dampak negatif terhadap tumbuh kembang. Terlihat jelas anak-anak lebih cepat beradaptasi dengan teknologi yang ada. Sehingga anakanak sering terlena dengan kecanggihan gadget dengan fitur-fitur yang tersedia di dalamnya. Anak-anak yang sering menggunakan gadget, seringkali lupa dengan lingkungan sekitarnya. Mereka lebih memilih bermain menggunakan gadget dari pada bermain bersama dengan teman-teman dilingkungan sekitar tempat tinggalnya. Sehingga interaksi sosial antara anak dengan masyarakat, lingkungan sekitar berkurang, bahkan semakin luntur.

Dampak negatif yang ditimbulkan dari penggunaan gadget di usia dini antara lain adalah pengaruh buruk sinar radiasi, kebiasaan menggunakan gadget akan membuat anak menjadi kecanduan gadget, membuat anak menjadi lambat dalam belajar, serta mempengaruhi perkembangan psikologis anak. Pancaran sinar dari gadget memberikan pengaruh yang tidak baik bagi kesehatan anak, salah satu buktinya adalah saat ini banyak kita jumpai anak usia SD bahkan TK yang sudah menggunakan kacamata

Sekolah yang dilakukan dalam kegiatan pengabdian ini, dilaksanakan di SDN 1 Tanjung Glugur Kecamatan Mangaran Kabupaten Situbondo. Seperti pada umumnya Sekolah Dasar, jam sekolah di sekolah ini berlangsung mulai pagi hingga siang. Di antara jam sekolah tersebut ada jeda untuk satu kali istirahat. 


\section{INTEGRITAS : Jurnal Pengabdian}

Vol 4, No 2, Desember 2020

ISSN $2580-7978$ (cetak) ISSN 2615 - 0794 (online)

Pada jam istirahat inilah biasanya siswa menghabiskan waktu dengan bermain gadget secara individu maupun kelompok. Lokasi yang biasanya ditempati oleh siswa untuk bermain gadget adalah lokasi yang tertutup atau jauh dari jangkauan perhatian guru. Hal ini dilakukan karena terdapat peraturan dilarang bermain gadget ketika di lingkungan sekolah. Tetapi masih ada beberapa siswa yang melanggar peraturan tersebut.

Lokasi kantor guru yang letaknya sedikit berjauhan dengan kelas, memberikan kesempatan yang lebih besar kepada anak-anak untuk bermain gadget, ditambah lagi terdapat fasilitias wifi hotspot yang bisa digunakan secara bebas oleh seluruh warga sekolah. Ketika jam istirahat guru juga tidak secara khusus memantau masing-masing siswanya. Akibat banyaknya siswa yang sering menggunakan gadget, tidak sedikit siswa yang menggunakan kaca mata akibat radiasi dari sinar gadget tersebut.

Untuk mengatasi dan mencegah fenomena gadget ini, tim pengabdi melakukan sosialisasi dalam kegiatan tentang dampak negatif dan cara penggunaan gadget dengan bijak untuk tingkat sekolah dasar. Kegiatan pengabdian ini menggunakan alat bantu berupa media promosi kesehatan untuk mempermudah dalam menyampaikan informasi kepada peserta serta media ini juga bisa digunakan untuk belajar sekaligus bermain sehingga para siswa sangat antusias dalam mengikuti kegiatan ini. Tujuan dari kegiatan pengabdian ini yaitu terdapat peningkatan pemahaman siswa tentang dampak buruk dan dampak baik penggunaan gadget. Siswa juga bisa memahami bagaimana menggunakan gadget dengan bijak.

\section{METODE PELAKSANAAN}

Pelaksanaan kegiatan pengabdian ini terdiri dari tahapan berikut:

\section{Tahap Persiapan}

Pada tahap persiapan, kegiatan yang dilakukan antara lain pemetaan masalah, pemilihan peserta. Pemetaan masalah dilakukan dengan mengumpulkan informasi tentang pola pergaulan anak SD dilingkungan sekitar khususnya di wilayah kecamatan Panji . Informasi tersebut dikumpulkan melalui diskusi dengan 


\section{INTEGRITAS : Jurnal Pengabdian}

Vol 4, No 2, Desember 2020

ISSN $2580-7978$ (cetak) ISSN 2615 - 0794 (online)

guru SD dan mahasiswa yang sudah melaksanakan PPL (Praktik Pengalaman Lapangan) di SD. Sedangkan, informasi tentang solusi dari pola yang terjadi dikumpulkan melalui diskusi dengan teman sejawat. Setelah dipilih sekolah mitra dalam kegiatan ini, dilakukan pemilihan peserta pelaksanaan PKM. Peserta yang dipilih adalah siswa kelas $\mathrm{V}$, dengan alasan siswa kelas $\mathrm{V}$ sudah bisa membaca dengan lancar, dapat berkomunikasi aktif dan mempunyai kesempatan yang lama untuk menyebar luaskan informasi ke teman dan lingkungannya sebelum lulus Sekolah Dasar.

2. Tahap Sosialisasi

Pada tahap sosialisasi dilakukan pelatihan untuk siswa tentang dampak penggunaan gadget. Pada Tahap sosialisasi, kegiatan yang dilakukan antara lain perkenalan dan memberikan angket kepada siswa, penyampaian informasi. Pelaksana memperkenalkan diri pada peserta PKM. Peserta berasal dari SDN 1 Tanjung Glugur Kecamatan Mangaran Kabupaten Situbondo, peserta difokuskan kepada kelas V karena siswa kelas V sudah bisa membaca dengan lancar, dapat berkomunikasi aktif dan mempunyai kesempatan yang lama untuk menyebar luaskan informasi ke teman dan lingkungannya sebelum lulus Sekolah Dasar. Pemberian angket dilakukan untuk mengetahui pengetahuan awal peserta akan dampak gadget sebelum dilakukan penyampaian informasi. Pada Penyampaian informasi dilakukan melalui media promosi kesehatan. Informasi yang diberikan adalah tentang dampak gadget pada anak-anak. Informasi ini terdiri dari dampak positif dan negatif gadget serta upaya-upaya untuk mencegah dampak negatif tersebut. Pada penutup juga dilakukan sesi Tanya jawab berhadiah bagi peserta yang menjawab benar pertanyaan yang diberikan.

3. Tahap Pendampingan Peserta

Kegiatan ini bertujuan agar peserta bisa secara mandiri memberikan informasi tentang dampak positif dan negatif gadget kepada seluruh lingkungan sekolah. Diharapkan dengan kegiatan pendampingan ini, tidak ada lagi siswa yang bermain gadget di lingkungan sekolah, bisa menggunakan gadget dengan bijak. Pendampingan dilakukan oleh tim pengusul dibantu mahasiswa. 


\section{INTEGRITAS : Jurnal Pengabdian}

Vol 4, No 2, Desember 2020

ISSN 2580 - 7978 (cetak) ISSN 2615 - 0794 (online)

4. Pemberian Sertifikat kepada peserta

Sertifikat ini sebagai bukti bahwa siswa tersebut telah melakukan pelatihan dampak penggunaan gadget di Sekolah Dasar, serta memberikan penghargaan kepada siswa tersebut.

\section{HASIL DAN PEMBAHASAN}

Kegiatan ini diikuti oleh siswa-siswi kelas IV dan V di SDN 1 Tanjung Glugur Kecamatan Mangaran Kabupaten Situbondo. Jumlah peserta yang hadir adalah 20 siswa. Peserta dikumpulkan di dalam 1 kelas yang sudah ditentukan oleh pihak sekolah.
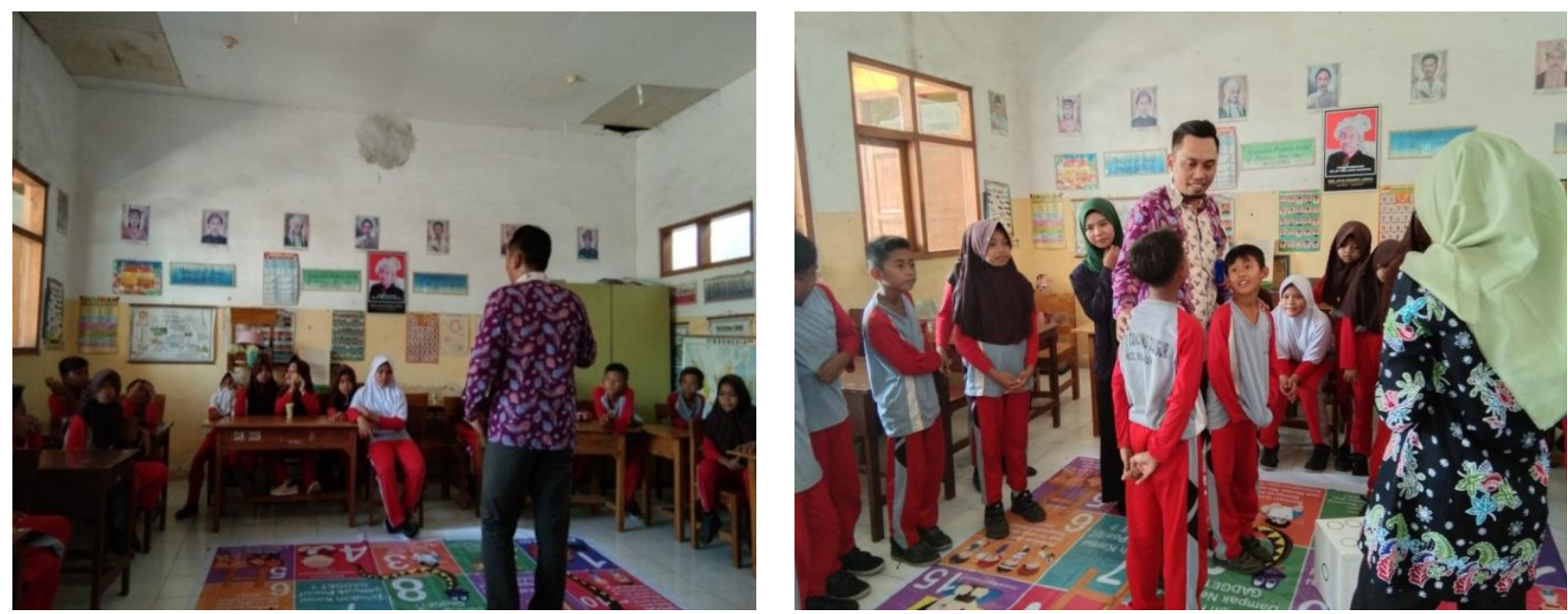

Gambar 1. Penjelasan Mengenai dampak Gadget

Jumlah peserta terdapat penambahan menjadi 20 orang dikarenakan antusias siswa dan sekolah yang sangat tinggi terhadap kegiata pengabdian. Kegiatan pengabdian ini dilaksanakan sesuai dengan metode pelaksanaan yang telah dirancang. Berikut deskripsi proses pelaksanaan tahapan kegiatan dalam PKM ini:

\section{Perkenalan}

Kegiatan diawali dengan perkenalan. Tim pengabdi menjelaskan tujuan dari kegiatan pengabdian masyarakat kepada peserta

\section{Pembagian Angket}

Setelah melakukan perkenalan, dilakukan pembagian angket untuk mengetahui pengetahuan awal peserta mengenai gadget. 


\section{INTEGRITAS : Jurnal Pengabdian}

Vol 4, No 2, Desember 2020

ISSN 2580 - 7978 (cetak) ISSN 2615 - 0794 (online)

\section{Penyampaian Materi}

Kegiatan Pengabdian kepada Masyarakat di SDN 1 Tanjung Glugur Kecamatan Mangaran Kabupaten Situbondo untuk memberikan informasi kepada siswa-siswi bagaimana menggunakan gadget dengan bijak, bahaya penggunaan gadget secara berlebihan bagi anak-anak dan dampak positif dari penggunaan gadget. Kegiatan pengabdian ini dilaksanakan untuk memberikan informasi kepada para siswa-siswi SDN 1 Tanjung Glugur agar tidak terjerumus kedalam perilaku yang menyimpang.

Kegiatan pengabdian ini menggunakan alat bantu berupa media promosi kesehatan untuk mempermudah dalam menyampaikan informasi kepada peserta serta media ini juga bisa digunakan untuk belajar sekaligus bermain sehingga para siswa sangat antusias dalam mengikuti kegiatan ini.

Media promosi kesehatan ini adalah media permainan ular tangga, media ini digunakan karena permainan ular tangga merupakan permainan tradisional yang murah, mudah dibuat, dan bisa mengajarkan anak untuk menanamkan sifat kerja sama, dan dapat berkompetisi secara sehat antar sesama teman.

Media ini berisi informasi mengenai gadget, seperti pengertian gadget, dampak negatif dan positif pemakaian gadget, jenis-jenis gadget, serta tips bagaimana menghindari diri dari dampak negatif gadget. Dari total 25 kotak permainan ular tangga ini, terdapat beberapa kotak yang berisi pertanyaan tentang gadget, misalnya menyebutkan dampak negatif gadget, siswa yang bisa menjawab pertanyaan dengan benar mendapatkan hadiah hiburan dari tim pengabdi. 


\section{INTEGRITAS : Jurnal Pengabdian}

Vol 4, No 2, Desember 2020

ISSN $2580-7978$ (cetak) ISSN $2615-0794$ (online)
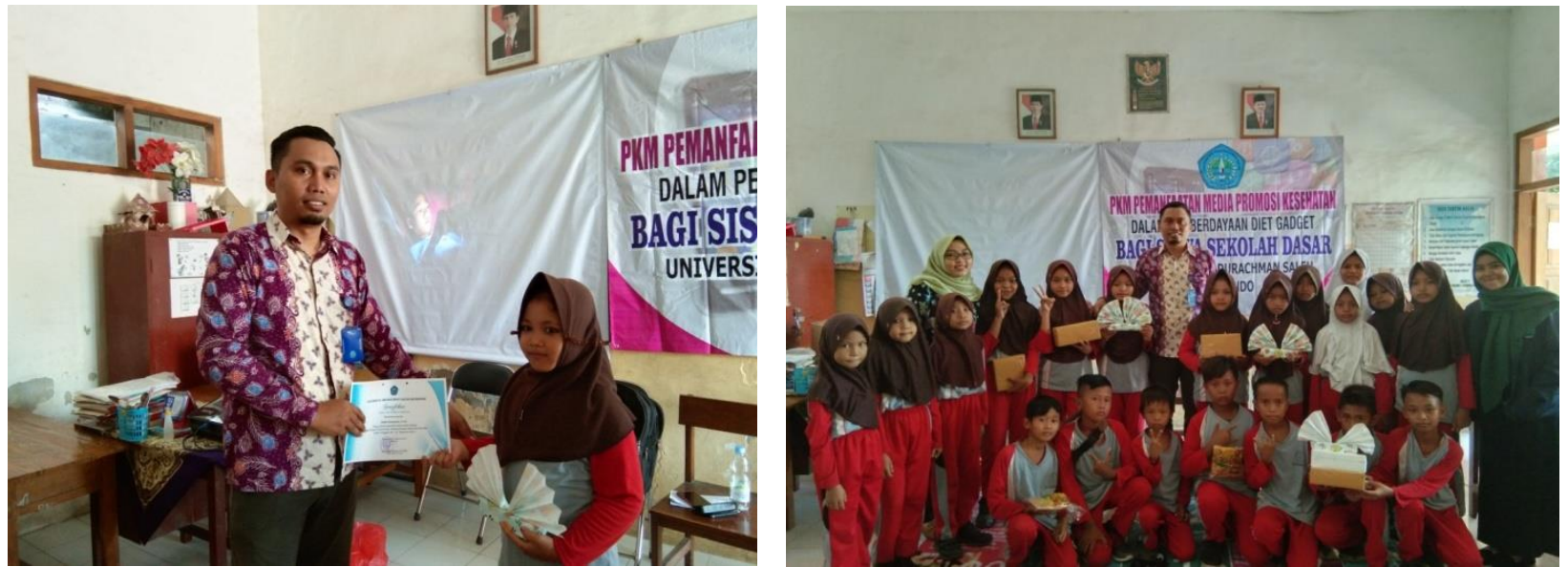

Gambar 2. Pemberian Sertifikat Kepada Peserta

Aturan permainan ini hampir sama dengan permainan ular tangga pada umumnya. Ada tiga tim yang menjadi pemain pada permainan ini. Masing-masing tim wajib menunjuk satu peserta untuk mewakili timnya untuk bermain permainan ular tangga ini. Peserta melempar dadu dan melangkah menuju kotak sesuai dengan jumlah angka yang keluar ketika dadu dilemparkan.

Apabila peserta berdiri tepat di kotak yang terdapat gambar tangga, siswa bergerak naik ke kotak yang di tuju. Kemudian apabila peserta berada di kotak dengan gambar kepala ular, peserta harus turun di kotak sesuai denga ekor ular. Pada media ini, hampir di setiap kotak memiliki istruksi yang berbeda beda. Peserta wajib membaca dengan keras instruksi yang tertera di gambar, kemudian tim dibantu mahasiswa menjelaskan maksud dari instruksi yang ada di kotak tersebut. Ketika menjelaskan instruksi tersebut, juga terjadi diskusi antara tim dan peserta. Seluruh peserta sangat antusias mengikuti kegiatan ini.

Evaluasi dari kegiatan ini yaitu tim melakukan pendampingan kepada siswa SDN 1 Tanjung Glugur. Pendampingan ini di lakukan selama 3 minggu. Setelah dilakukan pendampingan, terlihat siswa yang awalnya ketika jam istirahat selalu bermain gadget, sudah mulai meninggalkan gadget ketika di sekolah. Jam istirahat diisi dengan bermain yang melakukan aktifitas fisik, tetapi masih ada juga beberapa siswa yang membutuhkan pendampingan karena masih bermain 


\section{INTEGRITAS : Jurnal Pengabdian}

Vol 4, No 2, Desember 2020

ISSN $2580-7978$ (cetak) ISSN 2615 - 0794 (online)

gadget secara sembunyi-sembunyi, misalnya di dalam toilet, di halaman belakang yang jauh dari pengawasan guru.

\section{KESIMPULAN DAN SARAN}

Kegiatan pengabdian di SDN 1 Tanjung Glugur Kecamatan Mangaran Kabupaten Situbondo berjalan dengan lancar. Ini terlihat dari antusiasme kepala sekolah dan siswa-siswa sekolah dasar dalam mengikuti kegiatan ini. Pengetahuan siswa tentang pemahaman gadget terjadi peningkatan, ini terlihat dari pendampingan yang dilakukan oleh tim pengabdi selama 1 minggu. Diharapkan kegiatan seperti ini dapat dilakukan secara rutin di sekolah-sekolah lain, mengingat sebagian besar siswa dari peserta memiliki gadget dan tidak pernah mendapatkan informasi tentang dampak dari penggunaan gadget, serta kurangnya pengawasan dari orang tua dan guru.

Diharapkan adanya pengawasan dari orang tua dan guru ketika siswa menggunakan gadget. Guru juga sebaiknya memberikan pengawasan yang lebih ketika jam istirahat, dan memberikan teguran kepada siswa yang menggunakan gadget secara berlebihan ketika berada di sekolah.

\section{DAFTAR PUSTAKA}

ANGGRAHINI, S. A. 2013. Dinamika Komunikasi Keluarga Pengguna Gadget. Skripsi, Universitas Islam Negeri Sunan Kalijaga.

NURRACHMAWATI 2014. Pengaruh Sistem Operasi Mobile Android pada Anak Usia Dini. Makasar: Universitas Makasar.

USMI, W. Pentingnya Pendampingan Diologis Orang Tua dalam Penggunaan Gadget pada anak usia dini. Seminar Nasional Pendidikan Inovasi Pembelajaran untuk Pendidikan Berkemajuan, 2015 Ponorogo. FKIP Universitas Muhammadiyah Ponorogo. 